\title{
EFFECTIVENESS OFTOPICALINSULIN IN THE MANAGEMENT OF DIABETIC FOOT ULCERS.
}

\footnotetext{
1. MBBS, MS General Surgery, DSS (AUS),

Fellowship in Reconstructive Micro Surgery

Assistant Professor

Department of Surgery/Plastic Surgery

Baqai Medical University Karachi.

2. MBBS, MS General Surgery

Assistant Professor

Department of Surgery

Baqai Medical University Karachi.

3. MBBS, FCPS

Assistant Professor

Department of Plastic Surgery

Civil Hospital Karachi, DUHS.

4. MBBS

Lecturer

Department of Biochemistry

Karachi Medical \& Dental College

(KMDC).
}

Correspondence Address:

Dr. Shafaatullah

Department of Surgery/Plastic surgery

Baqai Medical University Karachi

shafaatullah007@Hotmail.com

Article received on:

07/03/2019

Accepted for publication:

25/06/2019

Received after proof reading:

$28 / 08 / 2019$

\section{Shafaatullah', Sadaf Iqbal², Bushra Zulfiqar ${ }^{3}$, Shayan Zufishan ${ }^{4}$}

ABSTRACT... Introduction: Diabetes mellitus is one of the most common metabolic disorders affecting a large part of our population. Apart from its effect on all organ systems, these metabolic derangements affect other processes in the body as well. Diabetic wounds are difficult to treat with conventional treatments. Delayed wound healing has led to increased morbidity and mortality in the population. Increased blood glucose leads to ineffective angiogenesis and less collagen deposition. In various studies long acting insulin zinc suspension has been shown to augment wound healing without any harmful effects. Objectives: To find out the advantages of topical insulin in the management of diabetic foot ulcers. Study Design: Observational study. Setting: Plastic Surgery and General Surgery Department, Baqai Medical University Karachi. Period: January 2014 to December 2016. Material and Methods: Patients visiting the Surgical OPD with diabetes mellitus and concomitantly having foot ulcers were included in the study. Diabetics having blood glucose levels of $110-130 \mathrm{gm} / \mathrm{dl}$ and ulcers measuring more than one $\mathrm{cm}$ on the dorsum of the foot were included in the study. All patients having foot ulcers were treated by daily topical spray of $1 \mathrm{cc}$ saline mixed with 5 units of insulin. This treatment was continued for 12 weeks or till the time ulcer was completely healed (whichever was earlier) and ulcer size was measured weekly. Ulcer size and depth before and after treatment was measured. Results: We had a total of 65 participants, among them there were 52 males and 13 females presenting with diabetic foot ulcer. Around $87.6 \%(n=57)$ patients had type 2 diabetes mellitus whereas $12.3 \%(n=8)$ patients had type 1 diabetes mellitus. Upon examination of the patient the location, size and depth of the ulcer was measured as well. These parameters were measured before and after treatment by topical insulin spray. Right foot ulcers were present in $64.6 \%$ of the patients and $35.38 \%$ patients had left foot ulcers. The mean size and depth of ulcer was $5.1 \pm 1.1 \mathrm{~cm}^{2}$ and $8.7 \pm 0.12 \mathrm{~mm}$ respectively. After treatment the mean size and depth of ulcer was found to be $1 \pm 0.04 \mathrm{~cm}^{2}$ and $1.4 \pm 0.12 \mathrm{~mm}$ respectively. Conclusion: There was significant improvement after treatment of diabetic foot ulcers with topical insulin spray. The wound size and depth were considerably decreased. This treatment had more promising results than conventional treatment methods for diabetic foot ulcers.

Key words: $\quad$ Diabetic Foot Ulcers, Delayed Wound Healing, Topical Insulin.

Article Citation: Shafaatullah, lqbal S, Zulfiqar B, Zufishan S. Effectiveness of topical insulin in the management of diabetic foot ulcers. Professional Med J 2019; 26(9):1487-1490. DOI: 10.29309/TPMJ/2019.26.09.3389

\section{INTRODUCTION}

Diabetes mellitus is one of the most common metabolic disorders affecting a large part of our population. Apartfromitseffectonallorgansystems, these metabolic derangements affects other processes in the body as well. ${ }^{1}$ Hyperglycaemia is the main reason behind the complications of diabetes mellitus. Most common complications of diabetes are retinopathy, nephropathy, neuropathy and cardiovascular diseases. Hyperglycaemia also affects wound healing and foot ulcers are a well-known complication of diabetes. Diabetes affects wound healing due to reduced collagen deposition and delaying the healing process. ${ }^{2}$ Diabetic wounds are difficult to treat with conventional treatments. Delayed wound healing has led to increased morbidity and mortality in the population. Increased blood glucose leads to ineffective angiogenesis and less collagen deposition. In various studies long acting insulin zinc suspension has been shown to augment wound healing without any harmful effects. ${ }^{3}$ Experiments with local insulin has shown to improve wound healing in diabetes. Insulin 
has also been found to reduce inflammation and accelerate wound healing. Insulin also causes rapid re-epithelization of the wound by promoting protein synthesis. Wounds unresponsive to conventional foot ulcer treatments have been shown to benefit by local insulin application but the accurate dose and concentration of insulin to be used is still under observation. ${ }^{4}$ Factors leading to poor wound healing are ineffective angiogenesis and increased blood glucose levels. CD34 is a transmembrane glycoprotein found in vascular epithelial cells, its detection by using anti CD34 indicates new vessel formation. Micro vessel density is also used to measure the expression of CD34 and it indicates angiogenesis. Effectiveness of the treatment of diabetic foot ulcers can be safely assessed by anti-CD34 and micro vessel density. ${ }^{5}$ Intralesional insulin injection has been found to restore collagen and promotes formation of granulation tissue. Insulin growth factor-1 deficiency is also associated with impaired angiogenesis. ${ }^{6}$ Experiments have shown that insulin administration over burns improves healing and tissue formation. Insulin increases proliferation of keratinocytes and fibroblasts, thus reducing healing time. ${ }^{7}$ Despite blood glucose control, $15 \%$ of patients will have non-healing diabetic ulcers at some time in their life. At molecular level, processes like cell adhesion, proliferation and differentiation are affected by insulin deficiency. ${ }^{8}$ Diabetics already have underlying neuropathy and angiopathy contributing to formation of foot ulcers. In the management of diabetic foot ulcers conventional therapies are found to be ineffective and they respond poorly. New therapeutic modalities to treat non-healing ulcers are skin grafts, hydrocolloid dressings providing good results. ${ }^{9}$ The aim of this study is to assess the effectiveness of topical insulin therapy in the healing of diabetic foot ulcers.

\section{MATRIAL AND METHOD}

This study was conducted in Baqai University Hospital Karachi during the time period of January 2014 to December 2016. This study was done at the Plastic Surgery and general surgery department, Baqai Medical University Karachi. Patients visiting the Surgical OPD with diabetes mellitus and concomitantly having foot ulcers were included in the study. Diabetics having blood glucose levels of $110-130 \mathrm{gm} / \mathrm{dl}$ and ulcers measuring more than one $\mathrm{cm}$ on the dorsum of the foot were included in the study. Ulcers were classified according to Wegener's classification and grade I and II ulcers were included in the study. Patients above the age of 70 years were excluded from the study. Ulcers of grade III or above were excluded from the study. Patients having peripheral arterial diseases were also excluded from the study. All patients having foot ulcers were treated by daily topical spray of $1 \mathrm{cc}$ saline mixed with 5 units of insulin. This treatment was continued for 12 weeks or till the time ulcer was completely healed (whichever was earlier) and ulcer size was measured weekly. Patients lost to follow-up were not included in the study. Ulcer size before and after treatment were compared and analysis was done using SPSS version 21 .

\section{RESULTS}

We had a total of 65 participants, among them there were 52 males and 13 females presenting with diabetic foot ulcer. Around $87.6 \% \quad(n=57)$ patients had type 2 diabetes mellitus whereas $12.3 \%(n=8)$ patients had type 1 diabetes mellitus. Table-Il shows the proportion of type of diabetes in patients with diabetic foot ulcer.

Upon examination of the patient the location, size and depth of the ulcer was measured as well. These parameters were measured before and after treatment by topical insulin spray. Right foot ulcers were present in $64.6 \%$ of the patients and $35.38 \%$ patients had left foot ulcers. The mean size and depth of ulcer was $5.1 \pm 1.1 \mathrm{~cm}^{2}$ and $8.7 \pm 0.12 \mathrm{~mm}$ respectively. After treatment the mean size and depth of ulcer was found to be $1 \pm 0.04 \mathrm{~cm}^{2}$ and $1.4 \pm 0.12 \mathrm{~mm}$ respectively. TableII

\begin{tabular}{|c|c|r|}
\hline Type of Diabetes & Frequency (n) & Percentage (\%) \\
\hline Type-1 & 8 & $12.30 \%$ \\
\hline Type-2 & 57 & $87.69 \%$ \\
\hline
\end{tabular}

Table-I. Type of diabetes mellitus in patients 


\begin{tabular}{|l|c|c|}
\hline \multicolumn{1}{|c|}{ Outcome } & $\begin{array}{c}\text { Before } \\
\text { Treatment }\end{array}$ & $\begin{array}{c}\text { After } \\
\text { Treatment }\end{array}$ \\
\hline Size of Ulcer $(\mathrm{cm} 2)$ & $5.1 \pm 1.1 \mathrm{~cm} 2$ & $1 \pm 0.04 \mathrm{~cm} 2$ \\
\hline Depth of Ulcer $(\mathrm{mm})$ & $8.7 \pm 0.12 \mathrm{~mm}$ & $1.4 \pm 0.12 \mathrm{~mm}$ \\
\hline \multicolumn{2}{|c|}{ Table-II. Size and depth of ulcer before and after } \\
treatment
\end{tabular}

\section{DISCUSSION}

Wound healing is a biological process involving chemotaxis, angiogenesis and collagen matrix formation. There are a lot of factors affecting the process of healing. Among these factors, bacterial contamination is the most important poor prognostic factor. Diabetic foot ulcers are more susceptible to bacterial contamination and increases complications. ${ }^{10}$ Recent studies show that topical insulin has a good role in treatment of chronic foot ulcers. Studies have shown significant improvement in healing time of foot. Wounded skin of rats treated by topical insulin cream has shown rapid healing due to proteins in the insulin signalling pathway. Topical insulin doesn't affect blood glucose levels and has no systemic side effects as well. ${ }^{11}$ Many studies have contributed to the recognition of insulin in wound healing, IGF a protein similar to insulin has shown similar benefits as insulin. In vivo studies have shown increased proliferation of fibroblasts and endothelial cells, along with deposition of extracellular matrix. ${ }^{12}$ In the $20^{\text {th }}$ century insulin was used to treat local hyperglycaemia, rather than wound healing purposes. A study conducted in India from 2010 to 2012 showed an interesting finding that larger wounds heal faster than smaller wounds i.e. the rate of wound healing is directly proportional to the area of the wound..$^{13}$ Negative pressure wound therapy was introduced a decade before and has become popular for wound healing purposes. It accelerates formation of granulation tissue, new vessel formation and re-epithelization. It also removes excess fluid and debris from the wound providing less bacterial contamination and good healing. It is indicated for treatment of chronic wounds, diabetic foot ulcers and burns. Multiple studies performed suggests that negative pressure wound therapy provides a high rate of healing, faster wound closure and augmenting granulation tissue formation. ${ }^{14}$ Negative pressure wound therapy along with insulin instillation into the wound has also been performed in some studies. Solutions initially used for this purpose was normal saline only. Other potential solutions used for it are insulin, phenytoin, sodium hypochlorite and polyhexanide. Belfield et al. treated chronic wounds with a mixture of $10 \mathrm{U}$ if zinc protamine insulin and base of ulcerin. The results of the study showed that this compound increases vascularization, decrease bacterial growth, less exudation, stimulated auto debridement and decreased healing time..$^{15}$ Zhang and colleagues used local insulin-zinc suspension, it showed promoting DNA synthesis in the wound, without any adverse effects on the body. ${ }^{16}$ Wilson et al. treated a case of chronic non-healing wound formed after laparotomy by topical irrigation of normal saline and soluble insulin. After 7 days of application, there was significant improvement and robust wound healing. Also, Rezvani and colleagues reported that topical insulin has higher rates of wound healing with insulin as compared to control groups, irrespective to the wound size. ${ }^{17}$ Collectively a number of factors are responsible for diabetic foot ulcer like uncontrolled diabetes, high blood glucose levels, neuropathy and infections. Diabetic angiopathy involves arterial system predominantly than any other vascular system in the body. Studies have shown that after topical insulin treatment, expression of CD34 and MVD was increased, showing increased vessel proliferation. ${ }^{18}$

\section{CONCLUSION}

There was significant improvement after treatment of diabetic foot ulcers with topical insulin spray. The wound size and depth were considerably decreased. This treatment had more promising results than conventional treatment methods for diabetic foot ulcers.

Copyright $\odot 25$ June, 2019.

\section{REFRENCES}

1. Park H, Copeland C, Henry S, Barbul A. Complex wounds and their management. Surgical Clinics. 2010; 90(6):1181-94. 
2. Dubay DA, Franz MG. Acute wound healing: The biology of acute wound failure. Surgical Clinics. 2003; 83(3):463-81.

3. Zhang X-j, Wu X, Wolf SE, Hawkins HK, Chinkes DL, Wolfe RR. Local insulin-zinc injection accelerates skin donor site wound healing. Journal of Surgical Research. 2007; 142(1):90-6.

4. Hallam M-J, Pitt E, Thomas A, Nduka C. Low-Dose insulin as an antiscarring therapy in breast surgery: $A$ randomized controlled trial. Plastic and reconstructive surgery. 2018; $141(4): 476 \mathrm{e}-85 \mathrm{e}$.

5. Zhang Z, Lv L. Effect of local insulin injection on wound vascularization in patients with diabetic foot ulcer. Experimental and therapeutic medicine. 2016; 11(2):397-402.

6. Aghdam SY, Eming SA, Willenborg S, Neuhaus B, Niessen $C M$, Partridge $L$, et al. Vascular endothelial insulin/IGF-1 signaling controls skin wound vascularization. Biochemical and biophysical research communications. 2012; 421(2):197-202.

7. Liu Y, Petreaca M, Martins $\square$ Green M. Cell and molecular mechanisms of insulin $\square$ induced angiogenesis. Journal of cellular and molecular medicine. 2009;13(11प12):4492-504.

8. Falanga $V$. Wound healing and its impairment in the diabetic foot. The Lancet. 2005; 366(9498):1736-43.

9. Swaminathan R. Effectiveness of topical insulin in management of chronic diabetic foot ulcers. Indian Journal of Basic and Applied Medical Research. 2014; $3(3): 455-9$.

10. Bing M, Da-Sheng C, Zhao-Fan X, Dao-Feng B, Wei L, Zhi-Fang $C$, et al. Randomized, multicenter, doubleblind, and placebo-controlled trial using topical recombinant human acidic fibroblast growth factor for deep partial thickness burns and skin graft donor site. Wound repair and regeneration. 2007; 15(6):795-9.
11. Saltiel AR, Pessin JE. Insulin signaling pathways in time and space. Trends in cell biology. 2002; 12(2):6571.

12. Sureshbabu A, Okajima H, Yamanaka D, Shastri $S$, Tonner E, Rae C, Szymanowska M, Shand JH, Takahashi SI, Beattie J, Allan GJ. IGFBP-5 induces epithelial and fibroblast responses consistent with the fibrotic response. Portland Press Limited; 2009.

13. Goenka G, Athavale VS, Nirhale DS, Deshpande N, Agrawal K, Calcuttawala M. Role of topical use of insulin in healing of chronic ulcer. Medical Journal of Dr DY Patil University. 2014; 7(5):579.

14. Blume PA, Walters J, Payne W, Ayala J, Lantis J. Comparison of negative pressure wound therapy using vacuum-assisted closure with advanced moist wound therapy in the treatment of diabetic foot ulcers: A multicenter randomized controlled trial. Diabetes care. 2008; 31(4):631-6.

15. Belfield W, Golinsky S, Compton M. The use of insulin in open-wound healing. Veterinary medicine, small animal clinician: VM, SAC. 1970; 65(5):455-60.

16. Scimeca CL, Bharara M, Fisher TK, Kimbriel H, Mills JL, Armstrong DG. Novel use of insulin in continuousinstillation negative pressure wound therapy as "wound chemotherapy". SAGE Publications; 2010.

17. Rezvani O, Shabbak E, Aslani A, Bidar R, Jafari $M$, Safarnezhad S. A randomized, double-blind, placebo-controlled trial to determine the effects of topical insulin on wound healing. Ostomy/wound management. 2009; 55(8):22.

18. Al-Rubeaan K, AIDerwish M, OuiziS, YoussefAM, Subhani $\mathrm{SN}$, Ibrahim HM, et al. Diabetic foot complications and their risk factors from a large retrospective cohort study. PloS one. 2015; 10(5):e0124446.

\section{AUTHORSHIP AND CONTRIBUTION DECLARATION}

\begin{tabular}{|c|c|c|c|}
\hline Sr. \# & Author-s Full Name & Contribution to the paper & Author $=\mathbf{s}$ Signature \\
\hline 1 & Shafaatullah & $\begin{array}{l}\text { Conception and design, Statistical } \\
\text { expertise, Critical revision of the } \\
\text { article for important intellectual } \\
\text { content. }\end{array}$ & \\
\hline 2 & Sadaf Iqbal & $\begin{array}{l}\text { Data collection critical revision of } \\
\text { the article for important intellectual } \\
\text { content. }\end{array}$ & \\
\hline 3 & Bushra Zulfiqar & Data collection. & \\
\hline 4 & Shayan Zufishan & Drafting of the article. & \\
\hline
\end{tabular}

